\title{
Perspectiva Docente Sobre a Utilização do Método Abacada para a Aprendizagem de Alunos com Deficiência Intelectual
}

\section{Teaching Perspective on the Use of the Abacada Method for Intellectual Disabled Students' Learning}

\author{
Joseli Maria Jofrea; Givan José Ferreira Santos*a; Silmara Morais Vargas David ${ }^{\text {b }}$ Cláudia Mara Silva
}

\begin{abstract}
aUniversidade Tecnológica Federal do Paraná, Programa de Pós-Graduação Stricto Sensu em Ensino de Ciências Humanas, Sociais e da Natureza. PR, Brasil.

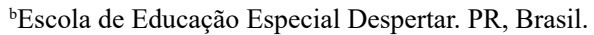

*E-mail: givansantos@utfpr.edu.br
\end{abstract}

\begin{abstract}
Resumo
As dificuldades encontradas no processo de alfabetização de alunos com necessidades educativas especiais motivaram a realização dessa pesquisa. O estudo teve como objetivo verificar se os alunos com deficiência intelectual, de uma Escola de Educação Básica na Modalidade Educação Especial do norte do Paraná, tiveram progressos na alfabetização com a utilização de determinada estratégia de ensino, popularmente conhecida como ABACADA. O estudo é pautado em pesquisa bibliográfica que elabora um breve histórico da Educação Especial no Brasil, os métodos de alfabetização que fundamentam a proposta e os resultados obtidos com uma pesquisa de campo, realizada durante três meses, por meio de um questionário com quinze professores que trabalham com a proposta de ensino desde 2017, na instituição supracitada. Na conclusão do trabalho, são demonstrados os resultados positivos obtidos para a alfabetização e apresentadas contribuições para aprimorar o processo de ensino-aprendizagem de alunos limítrofes ou com deficiência intelectual.
\end{abstract}

Palavras-chave: Educação Especial. Alfabetização. Estratégia de Ensino.

\begin{abstract}
The difficulties found along the literacy process of students with special educational needs motivated this research. The study aimed at verifying if students with intellectual disabilities, from a School of Basic Education in Special Education in the Northern of Paraná, had any progress at literacy with the use of a specific teaching strategy, popularly known as ABACADA. The study is grounded in bibliographic research that elaborates a brief history of Special Education in Brazil, the literacy methods that support the proposal and the results obtained with a field research, carried out during three months, through a questionnaire with fifteen teachers who have worked with a teaching proposal since 2017, at the aforementioned institution. At the work conclusion, the positive results applied to literacy and contributions to improve the students' teaching-learning process with limited or intellectual disabilities are shown.
\end{abstract}

Keyword: Special Education. Literacy. Teaching Strategy.

\section{Introdução}

A alfabetização representou e representa um avanço para a humanidade, no âmbito de proporcionar a emancipação pessoal, o aprimoramento da autonomia e a eficácia na comunicação (SOARES, 2018; CAGLIARI, 2010; TFOUNI, 2006). Desenvolver essas habilidades, ou partes dela em pessoas com deficiência intelectual, transtornos globais do desenvolvimento ou múltiplas deficiências, é um grande desafio para os docentes, assim, a escolha do método é importante para alcançar o objetivo de alfabetizar.

A alfabetização trata de um processo complexo, principalmente para os deficientes intelectuais, visto que sua forma de aprender é específica e requer um tempo diferenciado, portanto este artigo levanta a problemática: A proposta de ensino "Desafios do Aprender", conhecida como ABACADA, é eficaz na alfabetização de pessoas com deficiência intelectual? Essa proposta é destinada à alfabetização e apresenta alguns recursos didáticos para a compreensão da linguagem oral e posteriormente a aquisição do código escrito, trazendo para o centro das atividades discentes a consciência fonológica em seu nível silábico baseada no Método Fônico e no Método Sodré.

O objetivo desta pesquisa foi conhecer a eficácia da proposta na visão de alguns professores do processo de alfabetização. Com a interpretação das considerações de quem realiza a prática do processo de alfabetização de alunos com deficiência, foi idealizada a contribuição para o processo de ensino com discussões das possibilidades e dificuldades apresentadas.

Este estudo justifica-se pela dificuldade encontrada pela maioria dos professores da educação especial em alfabetizar seus alunos, pois o discente com deficiência intelectual, devido às suas dificuldades de aprendizagem, necessita de estratégias que o ajude principalmente na simbolização, para estabelecer relação do significante com o significado no processo de alfabetização.

\section{Material e Métodos}

Este estudo partiu de uma pesquisa bibliográfica, posto que foram utilizadas diversas publicações impressas e eletrônicas para fundamentar o assunto central abordado. De acordo com 
Richardson, a pesquisa bibliográfica é:

[...] o estudo sistematizado desenvolvido com base em material publicado em livros, revistas, jornais, redes eletrônicas, isto é, material acessível ao público em geral. Fornece instrumental analítico para qualquer outro tipo de pesquisa, mas também pode esgotar-se em si mesma (RICHARDSON, 1999, p.48).

A pesquisa apresentou um breve histórico da educação especial, algumas leis, documentos e conceitos sobre a deficiência intelectual e a fala de alguns autores renomados na área da alfabetização e a contextualização da proposta de alfabetização Desafios do Aprender pela própria autora Cláudia Mara.

Em seguida, empreendeu-se uma pesquisa de campo qualitativa com o propósito de saber quais os resultados obtidos pelos alunos com a estratégia de ensino ABACADA e se os professores usuários desse método recomendavam a sua continuidade. A pesquisa foi realizada em uma escola de Educação Básica na Modalidade Educação Especial, em uma cidade do norte do Paraná, que possui aproximadamente 112 alunos, com quinze professores, que trabalham ou já trabalharam com a proposta Desafios do Aprender.

No dizer de Tozoni-Reis (2009), a pesquisa de campo recolhe os dados no mesmo local onde ocorrem os fenômenos. A literatura científica elegeu o espaço escolar como o mais adequado para esse tipo de pesquisa. Contudo, outros espaços educativos também proporcionam importantes pesquisas que contribuem para a construção do saber educacional. A mesma autora esclarece que o uso do questionário reflete o maior grau de estruturação possível em entrevista. Assim, é importante que as questões estejam articuladas entre si, porém, uma questão não deve induzir a resposta da outra questão. O questionário aplicado junto aos professores continha duas perguntas:

- Quais são os resultados obtidos pelos alunos com a proposta Desafios do Aprender?

- Você recomenda a continuidade do uso do ABACADA na escola? Por quê?

\section{Resultados e Discussão}

\subsection{Breve histórico da Educação Especial no Brasil}

Durante boa parte da história da humanidade a deficiência, seja mental ou física, foi alvo de exclusão social, escolar e familiar, muitos deficientes eram escondidos, mortos ou abandonados. Entretanto nos últimos séculos, algumas pessoas reconheceram que todos podem aprender e têm esse direito.

Segundo Mazzotta (2019), a primeira obra impressa sobre educação de deficientes foi editada na França em 1620 com o título Redação das letras e a arte de ensinar os mudos a falar, de Jean-Paul Bonet, e a primeira instituição especializada para a educação de surdos-mudos foi fundada pelo Abade Charles M. Eppée, em 1770, que inventou o método dos sinais. Ainda segundo esse autor:

[...] educação especial é definida como a modalidade de ensino que se caracteriza por um conjunto de recursos e serviços educacionais especiais organizados para apoiar, suplementar e, em alguns casos, substituir os serviços educacionais comuns, de modo a garantir a educação formal dos educandos que apresentam necessidades educacionais muito diferentes das da maioria das crianças e jovens. Tais educandos, também denominados de "excepcionais", são justamente aqueles que hoje têm sido chamados de "alunos com necessidades educacionais especiais". Entende-se que tais necessidades educacionais especiais decorram da defrontação das condições individuais do aluno com as condições gerais da educação formal que lhe é oferecida (MAZZOTTA, 2019, p.11-12).

Mazzotta (2019) relata que as primeiras instituições do Brasil que atenderam pessoas com deficiências são do Rio de Janeiro, ambas fundadas por D. Pedro II, a primeira em 12 de setembro de 1854, O Imperial Instituto dos Meninos Cegos, e em 26 de setembro de 1857, o Instituto dos Surdos-Mudos. Desde então outras instituições foram criadas no Brasil, por exemplo: Instituto de Cegos Padre Chico (1928), Instituto Santa Terezinha (1929), Lar São Francisco (1943), Escola Municipal de Educação Infantil de $1^{\circ}$ Grau para Deficientes Auditivos Hellen Keller (1951) e em 1954 foi criada a primeira Associação de Pais e Amigos dos Excepcionais (APAE) no Rio de Janeiro. De acordo com a Federação Nacional das APAEs (2019), existem mais de 2.000 instituições espalhadas pelo Brasil.

Em 1961 o atendimento à pessoa com deficiência passou a ser norteado pela Lei Federal 4.024/61 - Lei de Diretrizes e Bases da Educação Nacional/LDB (BRASIL, 1961) que assegurou o direito da pessoa com deficiência à educação, preferencialmente dentro do sistema geral de ensino. Existia o direito, entretanto não existia uma inclusão real, então surgiu uma nova LDB, agora por meio da Lei Federal 5.692/71 (BRASIL, 1971), que acabou reforçando a ida destes alunos para classes especiais e escolas especiais.

A Constituição Federal de 1988, no seu artigo 206, inciso I (BRASIL, 1988), estabelece a "igualdade de condições de acesso e permanência na escola". Assim, esclarece que as escolas devem receber todas as crianças, independentemente de suas condições intelectuais, sociais, físicas, emocionais, linguísticas ou culturais.

$\mathrm{Na}$ década de 1990, movimentos sociais impulsionaram novas discussões e debates acerca dos direitos das pessoas com deficiência, alguns deles foram: a Conferência Mundial de Educação para Todos, em Jontien na Tailândia, em 1990, que tinha como propósito a erradicação do analfabetismo e a universalização do ensino fundamental; no ano de 1994 na cidade de Barcelona, na Espanha, aconteceu a Conferência Mundial de Necessidades Educativas Especiais: Acesso e Qualidade, que resultou na Declaração de Salamanca (BRASIL, 2019), documento que se caracteriza como uma política de justiça social.

O princípio básico que orienta a questão da educação em geral, após a Declaração de Salamanca, é o de que as escolas deveriam acomodar todas as crianças independentemente 
de suas condições físicas, intelectuais, sociais, emocionais, linguísticas ou outras (BRASIL, 2019). As instituições escolares deveriam incluir crianças deficientes e superdotadas, crianças de rua e que trabalham, crianças de origem remota ou de população nômade, crianças pertencentes a minorias linguísticas, étnicas ou culturais, e crianças de outros grupos desavantajados ou marginalizados. Tais condições geram uma variedade de diferentes desafios aos sistemas escolares. No contexto deste Sistema Educacional, o termo "necessidades educacionais especiais" refere-se a todas aquelas crianças ou jovens cujas necessidades educacionais especiais se originam em função de deficiências ou dificuldades de aprendizagem. Muitas crianças experimentam dificuldades de aprendizagem e, portanto, possuem necessidades educacionais especiais em algum ponto durante a sua escolarização. Escolas devem buscar formas de educar tais crianças de forma eficaz, incluindo aquelas que possuam desvantagens severas.

Em 1999 foi realizada a Declaração de Washington, nos Estados Unidos, intitulada Movimento da Vida Independente e dos Direitos das Pessoas Portadoras de Deficiência. Desde então, várias declarações, cartas e encontros foram feitos com a intenção de diminuir os preconceitos e resgatar os direitos das pessoas com deficiências em âmbito mundial.

Atualmente, as famílias precisam optar por matricular seus filhos com deficiência intelectual, transtornos globais do desenvolvimento, em escolas regulares da rede pública ou particular, outra possibilidade é a escola especial, seja pública ou particular.

\subsection{Alfabetização na Educação Especial}

De acordo com as Diretrizes Curriculares da Educação Especial do Estado do Paraná (BRASIL, 2006), a Educação Especial é uma modalidade de ensino que possui os mesmos princípios da Educação Básica. No entanto tal posicionamento é recente e por isso demanda atenção e diálogo entre toda a sociedade envolvida para que o aluno com necessidades educacionais especiais seja atendido em sua amplitude.

A compreensão da Educação Especial como modalidade que dialoga e compartilha os mesmos princípios e práticas da educação geral é recente e exige das famílias, alunos, profissionais da educação e gestores das políticas públicas um novo olhar sobre o aluno com necessidades educacionais especiais. Buscamos um novo olhar em que valores como compreensão, solidariedade e crença no potencial humano superem atitudes de preconceito e discriminação em relação às diferenças. Convidamos a um novo olhar que inspire a educação na e para a diversidade, em que currículos que marginalizam as diferenças dêem espaço à construção de práticas curriculares calcadas no compromisso com a pluralidade das manifestações humanas presentes nas relações cotidianas da escola (BRASIL, 2006).

Assim, enquanto direito de todos, a educação deve atingir a diversidade, deve sempre acreditar no potencial humano, onde o aluno que possui deficiência intelectual pode ser objeto transformador de sua realidade e assim fazer uso do conhecimento para melhorar sua qualidade de vida ao colocar em prática sua cidadania.

Atualmente a deficiência intelectual (DI) não é determinada apenas pelo Quociente Intelectual (QI), a Associação Americana de Deficiência Intelectual e Desenvolvimento (AAIDD, 2010) usa um modelo multidimensional baseado em cinco dimensões: habilidades intelectuais, comportamentos adaptativos, participação, papéis sociais, saúde e contexto. Portanto, a DI não está relacionada apenas à aprendizagem pedagógica, mas também à relação com o contexto social.

O diagnóstico de DI deve ser feito por uma equipe multidisciplinar e encaminhado à escola para a tomada de medidas que melhorem a qualidade de ensino-aprendizagem do indivíduo. Segundo Vygotsky (1998), a pessoa com deficiência possui capacidades e potencialidades, entretanto é preciso oferecer condições e ter um olhar individualizado para que tenham maiores oportunidades de mostrar seu potencial.

Ser um cidadão alfabetizado sugere que a pessoa se apropriou de um conjunto de habilidades, composta de diferentes abordagens, que possui características de fontes distintas. Devido à emancipação pessoal e autonomia que a alfabetização promove, a mesma tornou-se alvo de diversos estudos que investigam as variáveis existentes neste processo, para que tal conhecimento se efetive e o desafio de se alfabetizar os alunos com deficiência intelectual seja vencido. Assim, faz-se imprescindível a prática de propostas metodológicas diferenciadas nas escolas especiais e também em escolas regulares.

Tal flexibilização diz respeito à adequação dos objetivos propostos, à utilização de metodologias pertinentes ao ensino de determinado conteúdo, no uso de tecnologias assistivas e recursos humanos, no manuseio de materiais específicos, na adequação do tempo e reorganização do espaço para que esses alunos efetivem seu direito de aprender.

De acordo com Soares (2010), alfabetização é a aquisição da habilidade de codificação da fala em escrita, e corresponde a um processo de compreensão e expressão de significados. Assim, a maior parte dos estudos sobre a aquisição da linguagem se concentra na área psicológica, no que se refere ao enfoque dado aos processos psicológicos, fisiológicos e neurológicos na aprendizagem da leitura e escrita. Por essa mesma linha de pensamento, a história da alfabetização mostra que a justificativa de seu fracasso está relacionada à deficiência em alguma parte desse processo.

Da mesma forma, Carvalho (2019) diz que, no sentido restrito da aprendizagem inicial da leitura e escrita, a alfabetização é a ação de ensinar e o resultado de aprender o código alfabético, ou seja, as relações entre letras e sons. Essa definição pode se estender a interpretar leituras e produzir escritas, porém nesse artigo utiliza-se como sinônimo de codificação da fala em escrita.

Em âmbito mundial, o tema alfabetização despertou variadas pesquisas sobre seu aspecto teórico e metodológico, de modo a descobrir um método mais eficaz para o ensino da leitura e escrita. Mortatti (2000) relata que, até a década 
de 1970, as pesquisas centravam-se em métodos sintéticos, analíticos ou mistos. Nas ponderações de Carvalho (2019), os métodos sintéticos são os que partem da letra, da relação entre letra e som, ou da sílaba, para se conseguir chegar à palavra. Já os métodos analíticos vêm pelo lado oposto, trazem a premissa de se trabalhar de uma forma global, com ponto de partida em unidades maiores, como o conto ou a frase. Uma terceira opção seria os métodos mistos, ou analíticosintéticos, que combinam abordagens de ambas as técnicas citadas anteriormente.

A proposta de alfabetização Desafios do Aprender, mencionada nesse artigo, deriva do Método Fônico Silábico e do Método Sodré que, por sua vez, fazem parte dos meios sintéticos de aprendizagem. Segundo sua idealizadora, a professora alfabetizadora Cláudia Mara Silva, esse processo acontece de forma sistemática, ordenada e progressiva, de passo em passo, respeitando o ritmo de cada aluno. Talvez esse tenha sido o fator que despertou o interesse em algumas Escolas de Educação Especial em adotá-lo, já que as Diretrizes para um Currículo Inclusivo apontam que:

[...] o desafio da participação e aprendizagem, com qualidade, dos alunos com necessidades educacionais especiais, seja em escolas regulares, seja em escolas especiais, exige da escola a prática da flexibilização curricular que se concretiza na análise da adequação de objetivos propostos, na adoção de metodologias alternativas de ensino, no uso de recursos humanos, técnicos e materiais específicos, no redimensionamento do tempo e espaço escolar, entre outros aspectos, para que esses alunos exerçam o direito de aprender em igualdade de oportunidades e condições (BRASIL, 2006, p.9)

Alfabetizar alunos com deficiência intelectual é um desafio para a escola e também para o docente que deve estar preparado para atender as necessidades educacionais dos seus alunos, buscando a melhor forma, o melhor método para conseguir manter seu aluno estimulado a ler e escrever, pois todos são capazes de aprender.

\subsection{Proposta de ensino Desafios do Aprender}

A Professora Cláudia Mara da Silva, atuando por mais de 30 anos na Educação Especial, percebeu a necessidade de um trabalho efetivo na área da leitura e escrita que possibilitasse a apropriação desse conhecimento por alunos que há vários anos frequentando a escola não apresentavam avanço significativo no processo de aprendizagem da leitura e escrita. Essa busca por um trabalho que efetivamente trouxesse solução para a aprendizagem resultou no estudo de dois métodos de alfabetização: Método Fônico e Método Sodré, métodos esses que fundamentaram o ABACADA.

Esta é uma proposta voltada para alunos do Primeiro Ano do Ensino Fundamental, para alunos com Dificuldades de Aprendizagem, para Educação de Jovens e Adultos e alunos com Deficiência Intelectual, alunos esses que com a inclusão frequentam a escola comum e muitas vezes não obtêm êxito na aprendizagem da leitura e escrita.
O ABACADA apresenta os recursos didáticos utilizados para a compreensão da linguagem oral e à aquisição do código escrito. Evidencia o desenvolvimento e aplicação da consciência fonológica, pressupondo que essa prática enriquecerá e aprimorará a utilização da sílaba na palavra como recurso de estudo, levando o aluno a interagir e assimilar a fala, o ato de ler e de escrever.

O desenvolvimento deste método está atrelado aos benefícios de se trabalhar com o desafio de forma lúdica, na utilização de vários jogos de sílabas, palavras, frases e textos. Cláudia salienta que esta forma de trabalhar colabora para o desenvolvimento cognitivo, a autonomia e a construção da autoestima.

Os recursos didáticos são apresentados com orientação de uso para que sejam introduzidos no cotidiano escolar e gerem reflexões sobre a apropriação do código escrito e do modo como os alunos aprendem. O aluno com déficit intelectual, devido às suas dificuldades de comunicação e expressão, que é imprescindível à construção da leitura e da escrita, necessita de estratégias que os ajudem na simbolização, que estabeleça a relação do significante com o significado.

Inicialmente, trabalha-se com as sílabas canônicas, formadas por consoantes e a vogal A. Nessa fase inicial, o aluno começa a compreender o processo da leitura e escrita, partindo assim para a construção de palavras, e nesta sistematização o aluno vai aos poucos ganhando segurança e confiança para prosseguir.

Quando o aluno apresenta avanços, parte-se para a construção de frases, ainda com a vogal A, e finalmente o texto, dessa forma dá-se sistematização do método: sílabas com A, palavras com A, frases com A, textos com a vogal A. Ao término das atividades com a vogal A, segue-se com a apresentação das sílabas com $\mathrm{O}$, depois $\mathrm{U}$, seguidas pelo I, e, por fim, com a vogal E. Sequência esta que se encontra na Apostila de Alfabetização, volume I, de autoria da professora Cláudia Mara, conforme mostra a Figura 1.

Figura 1 - Painel de alfabetização ABACADA
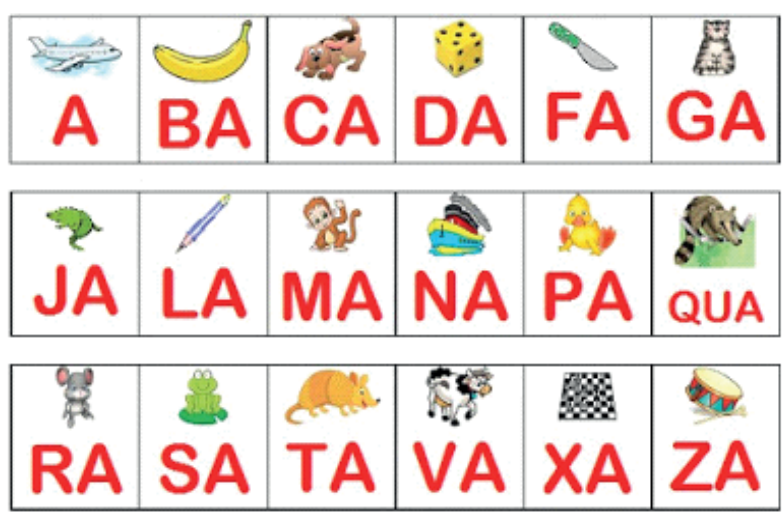

Fonte: Silva (2019).

As atividades que o material propõe são desafiadoras, porém, simples, objetivas e de fácil entendimento. Faz parte da proposta uma variedade de jogos. Jogos para o trabalho 
com as sílabas: bingo de sílabas, bingo de figuras, painel das sílabas, formação de sílaba e outros. Jogos para o trabalho com as palavras: baralhos, bingos, formação de palavra, caçapalavras, enfim uma variedade de jogos e atividades para trabalhar com todas as etapas da proposta de alfabetização.

Seguir os caminhos do aprender é um desafio para pessoas com deficiência intelectual ou que apresente dificuldade. Claudia Mara da Silva afirma que quem ensina precisa acreditar na capacidade do aprendiz, foi assim que surgiu o ABACADA, que acredita na possibilidade de aprendizagem de todo ser humano, independente de sua condição intelectual.

Quanto à primeira pergunta apresentada aos professores, como pontos positivos em relação ao emprego da estratégia de ensino, foram unânimes em afirmar que: os alunos conseguiram compreender melhor a escrita e leitura de palavras; a memorização das sílabas aliada à imagem simplificou a compreensão da formação das palavras; proporcionou uma evolução em boa parte dos alunos que ainda não estavam alfabetizados.

Uma das participantes respondeu: "Acredito que o método facilitou a aprendizagem dos alunos devido à maneira como é trabalhado com os alunos, de modo bem claro, associando as sílabas com as figuras, enfim achei bem significativo." Assim, a participante entra em comunhão de pensamentos com Soares (2019; 2010), que conceitua a alfabetização como a aquisição da habilidade de codificar a fala em escrita com expressão de significados.

Outra professora expressou: "Baseada na experiência que obtive utilizando o método ABACADA, percebi que os alunos conseguiram assimilar de forma mais fácil as letras, as sílabas e formar as primeiras palavras". Esse relato abona a validade do método sintético do ABACADA (CARVALHO, 2014), que parte da aprendizagem de unidades linguísticas escritas menores para maiores pelos alunos. Algumas professoras relataram que os alunos demonstraram mais entusiasmo quando passaram a estudar com o ABACADA, sendo a motivação um fator essencial para qualquer processo de aprendizado, o fato de se possuir um material simples, concreto e colorido de uso pessoal contribuiu para o entusiasmo relatado.

Outra professora enfatizou o processo de inclusão: "Por ser um método inovador e inclusivo, os alunos demonstram maior interesse e consequentemente bons resultados na atenção, na aquisição do vocabulário, na discriminação auditiva, no reconhecimento das sílabas e na leitura e escrita." Os professores mencionaram ainda que muitos alunos só conseguiram soletrar as letras e, depois da memorização das sílabas prontas, foi como se de repente algo mágico tivesse acontecido na mente de alguns alunos, pois apenas juntando duas sílabas já conhecidas por eles, passaram a formar palavras e se sentiram mais estimulados a estudar, já que alguns há vários anos estavam neste estágio, a soletração.

Os docentes continuaram explicando que a introdução gradual dos fonemas, começando pela letra A em cada sílaba, por um lado facilitou a aprendizagem devido à memorização ser mais fácil, entretanto por outro lado alguns alunos com maior comprometimento intelectual permaneceram nestas mesmas sílabas, não conseguindo avançar para a próxima vogal que é a letra $\mathrm{O}$ e também não conseguiram nem mesmo formar palavras reconhecendo apenas algumas sílabas.

Em relação à segunda pergunta respondida pelos professores, a respeito da recomendação da continuidade do método $\mathrm{ABACADA}$, todos posicionaram-se favoráveis à sua permanência, com a observação de que esta proposta ainda está em fase de experimentação e são necessárias várias etapas para que o aluno conclua a aprendizagem de todo o processo. Uma das professoras disse: "Sim, porque é um método criado e pensado para pessoas com deficiência intelectual e está dando certo. todo material incluindo apostilas e jogos é eficiente para a aprendizagem dos nossos alunos".

Ainda acrescentaram que o método respeita o tempo de aprendizagem de cada aluno e que mesmo os que não se alfabetizaram tiveram avanços, seja na memorização, na compreensão, na oralidade ou mesmo pelo fato de manusear e ter contato com materiais específicos para a condição de aprendizagem deles: "Sim, pelo fato de que os alunos se sentem valorizados tendo materiais como a apostila, feitos especialmente para eles", ponderou uma professora. Também sugeriram a continuidade da proposta ABACADA para os alunos que concluíram a apostila de alfabetização.

Essas considerações dos professores sobre práticas bemsucedidas com o suporte didático "Desafios do Aprender" são coerentes com os princípios postulados por documentos oficiais sobre Educação Inclusiva no Brasil.

\section{Conclusão}

A deficiência intelectual faz parte da humanidade, entretanto ela não deve servir para classificar tampouco marginalizar pessoas, cada indivíduo é singular e importante socialmente. Aqueles que apresentam dificuldades para se alfabetizar conquistaram avanços, nas últimas décadas houve melhoras em relação às políticas educacionais que atendam às suas necessidades; estudos e pesquisas estão buscando entender quais os melhores métodos para que a aprendizagem se efetive.

Ao se pensar assim, foi feito uma pesquisa sobre a estratégia de ensino ABACADA, para saber se ela é eficaz na alfabetização de pessoas com deficiência intelectual. Consoante às respostas dos professores, constatou-se o avanço dos alunos e sua eficácia, a estratégia ajuda na simbolização, assim o aluno consegue estabelecer relação entre o significado e o significante e se alfabetizar.

É fato que nem todas as pessoas com deficiência intelectual, principalmente os casos mais severos, conseguirão se alfabetizar com a estratégia ABACADA, entretanto ela é pensada justamente para quem realmente apresenta mais dificuldade de aprender, pois aumenta suas possibilidades de 
alfabetização.

Ao ver a evolução das pessoas com necessidades educacionais especiais na escola de educação especial, com a proposta de ensino Desafios do Aprender, sugere-se que a mesma seja utilizada também no ensino regular. É provável que os alunos considerados "limitados" no ensino comum aprendam com o ABACADA, lembrando que existem muitos alunos inclusos que poderão se beneficiar com essa proposta de ensino.

\section{Referências}

AAIDD - American Association on Intelectual and Developmental Disabilities Intelectual. Desability, Definition, Classification, and Systems of Suports. 2010. Disponível em: https://aaidd.org/ intellectual-disability/definition. Acesso em: 3 abr. 2020.

BRASIL. Constituição da República Federativa do Brasil. Brasília: Senado Federal, Centro Gráfico, 1988.

BRASIL. Lei de Diretrizes e Bases da Educação Nacional. Lei n 4.024/61, de 20 de dezembro de 1961.

BRASIL. Lei de Diretrizes e Bases da Educação Nacional. Lei n 5.692/71, de 11 de agosto 1971.

BRASIL. Lei de Diretrizes e Bases da Educação Nacional. Lei n 9.394/96, de 20 de dezembro de 1996.

BRASIL. Ministério da Educação MEC. Secretaria de Educação Especial. Declaração de Salamanca. Brasília: MEC, 2019.

CAGLIARI, L.C. Alfabetização e linguística. São Paulo:
Scipione, 2010.

CARVALHO, M. Alfabetizar e letrar: um diálogo entre a teoria e a prática. Petrópolis: Vozes, 2019.

FEDERAÇÃO NACIONAL DAS APAES. Disponível em: https://apaebrasil.org.br/page/2. Acesso em: 5 maio 2019.

MAZZOTTA, M.J.S. Educação Especial no Brasil: história e políticas públicas. São Paulo: Cortez, 2019.

MORTATTI, M.R.L. Os sentidos da alfabetização. São Paulo: UNESP; CONPED, 2000.

RICHARDSON, R.J. et al. Pesquisa social: métodos e técnicas. São Paulo: Atlas, 1999.

SEED. Diretrizes Curriculares da Educação Especial para a Construção de Currículos Inclusivos. Brasil: Curitiba: SEED, 2006.

SILVA, C.M. Desafios do aprender. 2019. Disponível em: http:// abcclaudiamara.blogspot.com/. Acesso em: 5 maio 2019.

SOARES, M. Alfabetização e letramento. São Paulo: Contexto, 2018.

SOARES, M. Letramento: um tema em três gêneros. Belo Horizonte: Autêntica, 2010.

TFOUNI, L.V. Letramento e alfabetização. São Paulo: Cortez, 2006.

TOZONI-REIS, M.F.C. Metodologia da pesquisa. Curitiba: IESDE, 2009.

VYGOTSKY, L.S. A formação social da mente. São Paulo: Martins Fontes, 1998. 